\title{
Contemporary Permanent Luting Agents Used in Dentistry: A Literature Review
}

\author{
Ebru SÜMER ${ }^{1}$, Yalçın DEĞER ${ }^{2}$ \\ ${ }^{1}$ Assistant, Dicle University, Faculty of Dentistry, Department of Prosthodontics, Diyarbakır, TURKEY \\ ${ }^{2}$ Assist. Prof., Dicle University, Faculty of Dentistry, Department of Prosthodontics, Diyarbakır, TURKEY
}

\section{Key Words}

Dental cements, luting agents, adhesive resin cement, resin modified glass ionomer cement.

\section{Correspondence: \\ Ebru SÜMER \\ Dicle University, Dental Faculty, Department of Prosthodontics, 21280 Diyarbakir, Turkey \\ e-mail: \\ dt_ebrusumer@hotmail.com}

\begin{abstract}
Dental cements are widely used in dentistry. Base material, temporary filling material and luting agents can all have different clinical applications. Different types of cement have also been developed for various orthodontic and endodontic treatments.

In literature it is still argued that there is not ideal cement answering all purposes yet, so different materials are required for the comprehensive patient treatments and it is not always that easy to make the best choice.

The aim of this article is to provide a clinically relevant discussion of contemporary permanent luting agents, in order to enhance the dentist's ability to make proper cementation choices and application.
\end{abstract}

(Int Dent Res 2011;1:26-31)

\section{Introduction}

Dental cements are widely used in dentistry. They can all have different clinical uses in dentistry. Cements can be used as base material, temporary filling material and luting. There are also different types of cements developed to be used in orthodontic and endodontic treatments (1).

Cements used as base material protect pulp from thermal, electrical and chemical effects $(1,2)$. Cements are used as temporary filling material cover the cavity hermetically and protect the tooth from external effects till the next clinic seance. Luting cements are used in adapting the tooth to indirect restorations prepared out of mouth (2). Luting agents may be permanent or temporary, depending on their physical properties and the planned longevity of the restoration (3).

In literature it is still argued that there is not ideal cement answering all purposes yet, so different materials are required for the comprehensive patient treatment and it is not always that easy to make the best choice (4).
Zinc phosphate, zinc oxide eugenol and silicophosphate cements were used from the early twentieth century till 1970s when new cements were developed. At first polycarboxylate cement, next glass ionomer cements and within the last thirty years resin cements and resin modified glass ionomer cements were developed (5).

\section{Qualities of Ideal Cement}

Basic mechanical, biological, and handling requirements must be met by the cement $(2,3,6$, 7):

1. It should be well adapted to living dental tissues, it should contain no pulp irritating toxic material and it should further have anticariogenic qualities,

2. It should have very low resolution ratios within the liquids inside the mouth,

3. In order to reach the smallest details between restoration and tooth, it should possess low viscosity and film thickness, 
4. It should be resistant against mastication forces and pulling forces formed through the effect of gummy foods,

5. It should have sufficient light transparency,

6. It should provide sufficient heat insulation to protect living tooth from thermal effects,

7. It should give sufficient working time and be easy to manipulate,

8. It should be able to bond to hard dental tissues,

9. It should have a long shelf-life.

Ensuring optimal resistance and retention in tooth preparation has primary importance but still the cement should act like a barrier against microbial leakage, it should completely fill the tooth and restoration interface and protect the bond between restoration and tooth against mechanical and chemical effects (6).

All the permanent luting cements on market have these qualities to some extent, but each type of cement displays different physical attributions with respect to their own substance (3).

\section{Retention and Bonding}

Mechanical interlocking with rough surfaces on a parallel wall preparation is the principal means of retention for luting cement, regardless of chemical composition (3). Luting mechanisms of cements are three types; chemical, mechanical and micromechanical. Retention of restoration is obtained, depending on the quality of applied cement, through combining two or three of these mechanisms (8).

\section{Classification}

Cements are mostly in the form of powder and liquid and their setting reaction is an acid-base reaction. Liquid acts like acid and powder acts like base. Aside from resin cements composed after polymerization of macromolecules, these cements that are set through acid-base reaction are classified as acid-base cements (AB Cements) (3).

The literature varies considerably on the classification and discussion of cements. Craig followed a traditional classification that grouped cements with respect to their chief ingredients (ie, zinc phosphate, zinc silicophosphate, zinc oxideeugenol, zinc polyacrylate, glass-ionomer and resin), whereas O'Brien classified dental cements by matrix bond type (ie, phosphate, phenolate, polycarboxylate, resin and resin modified glass ionomer). Donovan simply divided cements into conventional (zinc phosphate, polycarboxylate, glass-ionomer) and contemporary (resin-modified glass-ionomers, resin) based on knowledge and experience using these materials (Table 1$)(1,3)$.

\section{CONTEMPORARY PERMANENT LUTING AGENTS}

\author{
Resin Modified \\ Glass Ionomer Cements
}

Despite the positive aspects of glass ionomer cements that have been used in dentistry since the seventies till present day, in order to improve some of their qualities and eliminate the disadvantages, resin modified glass ionomer cements (RMGIC) were developed in the late eighties by adding resin into glass ionomer cements $(2,3)$.

Their contents are basically $80 \%$ glass ionomer cement and $20 \%$ resin and there may be some changes with respect to differences in brand. HEMA of which liquid is polymerized via light (Hydroxy ethyl methacrylate), methacrylate groups (EGMA, GMA and Bis-GMA etc.), tartaric acid, polyacrylic acid and water. Its powder however contains fluoro aluminosilicate glass particles. The qualities of resin modified glass ionomer cement are between conventional glass ionomer cements and composite resins which means RMGIC is a hybrid material (2).

The polymerization of methacrylate units in cement can start with light or chemically (6). In dual cure materials HEMA's polymerization starts with light activation and slower progressing acid base reaction continues to better strengthen the material and increase the resistance. In tricure materials however there is a chemical indicator for HEMA and HEMA's polymerization starts chemically, next a matrix strengthened via progressive acidbase reaction takes place $(2,9)$. Compared to dual cure cements, the advantages of cements with tricure setting mechanism are the extra chemical polymerization of resin and the occurrence of polymerization in the places where light cannot reach (2). In the set cement there are two matrixes within each other. One is ionic matrix formed through acid-base reaction and the other one is resin matrix (10).

These cements have compressive and diametral tensile strengths greater than zinc phosphate, polycarboxylate and some glass ionomers but less than resin composite. Their adhesion to enamel and dentin, and their fluoride release pattern is similar to glass ionomer cements (6). Due to the carboxyl groups in the polyalcenoic acid within them, RMGIC contain adhesive features (9). On that account there is no need for a bonding agent between the tooth and material (10).

Applying dentine polyacrylic acid conditioner prior to RMGIC application not only improves wettability of dental surface but it also enables 
hydrogen bond formation and strengthens the cement and ionic change (10).

Their abrasion resistance and fracture resistance are greater than GICs (Glass Ionomer Cements) and (20) they have better aesthetical features than GICs (2). Compared to GICs these cements are more resistant against water contamination during setting reaction and have low level of solubility. Another advantage of resin modified glass ionomer cements is their ease of mixing and use, because multiple bonding steps are not required. They also have adequately low film thickness (6).

In resin ionomer cements, moving the excess cement after cementation constitutes a great problem. Therefore soon after the primary setting reaction, unreacted materials below restoration margins need to be cleaned (3).

In these cements, resin addition has not significantly lowered dehydration resistance of glass ionomer content. Besides the most important disadvantage of resin ionomers is that due to polyHEMA with hydrophilic character water absorption, plasticity and hygroscopic expansion are increased. Water absorption in the beginning lessens the stress during polymerization shrinkage but water absorption that continues creates a harmful effect. As it displays significant dimensional changes, these cements are not applicable to use in full ceramic feldspathic-type restorations and post cementation $(6,9)$.

Resin ionomers can be used in cementation of metal, metal-porcelain, crown and bridges, supporting amalgam, composite and glass ionomer cores as well as base material under composite fillings. They have different types developed for orthodontic applications as well $(5,6)$. Resin modified glass ionomer cements are available in the market as powder-liquid and automix capsule (5).

\section{Polyacid Modified \\ Composite Resin Cements}

Resin addition to conventional glass ionomer cements pioneered the development of a different group of luting cements. This group is somewhere between classical GICs and composite resins (3).

Polyacid modified composite resins were defined at the end of 1990 s as a composite of (compomer) composite resin (comp) and glass ionomer (omer) (3). Physical qualities of compomers are closer to composite resins (11).

The material which at first is polymerized through light then meets water absorption in mouth and similar to chemical GICs, they set at the end of acid-base reaction (10). However since in compomers no salt matrix and hydrogel are formed (in glass ionomer cements with the effect of water that emerges when acid-base reaction starts salt matrix containing the salts of polycarboxylic acid is formed and the surface of glass particles turns into silica hydrogel) they cannot act like fluoride reservoir hence their fluoride release is restricted (2). Without etching process, only with their unique bonding agents, they bond to the hard tissue of tooth and release fluoride to the adjacent dental tissues (10).

Their compressive and flexural resistance is greater than RMGICs but lower than composite resins. Without applying bonding agent, adhesion of compomers to tooth is limited (3). Bonding agent within sets of compomers are mostly one-phase bonding systems that combine primer and adhesive mostly in one single bottle (2).

\section{Resin Cements}

Resin cements are one type of composite consisting of resin matrix and filler inorganic particles (9). The bonding between resin matrix and fillers are created via inter phase agent. This inter phase agent consists of long chain molecule silanes of which organic silica component. That means resin cements consist of three phases that are structurally different; organic phase, inorganic phase and inter phase (10). With the lower filling structure and viscosity in their context, they differ from restorative composites (9).

In a good number of resin cements, there are glass or silica particles varying between the ratios of 20\%-80\% (3). Silica particles strengthen mechanical qualities of mixture, they permeate and diffuse the light (10). These fillers make it possible that cement is more resistant against compressive and tensile forces and perform low solubility (6).

With respect to filler size, composite resin cements are classified into two groups as with micro filler (about $0.04 \mu \mathrm{m}$ ) and hybrid composites (about 0.7-1.7 $\mu \mathrm{m})(21)$. In-vitro researches analyzed the effect of filling particles inside resin cement on the physical attributions of cement. It has been detected that compared to resin cements containing hybrid type filler, resin cements with micro fillers have greater resistance against wear (22).

Biological compatibility and physical qualities of resin cements do not only depend on the quality and quantity of varying polymer and inorganic materials inside, but they are also closely related to the curing mechanism of resin (12).

Resin cements can be activated chemically or via visible light or by both chemical and light (dual cure). They have a variety of types in different colors and opacities (6). Amongst them the most ideal one is, with respect to polymerization conditions, light + chemical curing system (18). Resin cements that are chemically polymerized have been produced in double paste system or in the form of powder-liquid. Polymerization starts 
chemically by mixing two components. In paste system, in one of the paste there is benzoyl peroxide initiating polymerization and in the other one there is tertiary amine speeding up polymerization. Resin cements that are polymerized with light have been produced in single paste system. In these cements, as light absorber, there is camphorquinone and as accelerator there is aliphatic amine. Dual cured resin cements have been produced as two paste or in powder-liquid form. In their structure there is both a polymerization starter (camphorquinone) and chemical activator components (peroxytamine) (10).

Due to their chemical structures they provide adhesion with tooth tissues. The bonding of resin to enamel is achieved through micromechanical interlocking of resin to hydroxyapatite crystals and acidic enamel prisms. Bonding to dentin is however more complex; it is achieved through penetration of hydrophilic monomers to partially demineralized apatite structure of etched dentin. Hence adhesion is created via micromechanical interlocking of resin to hybrid layer or resin diffusion zone $(6,9)$.

Bonding to dentin requires multiple phases. Since total etching systems frequently cause postoperative sensitivity, less invasive self etching systems have been developed. Through the application of self etching systems, the number procedures to follow decreases $(13,22)$.

Polymerization shrinkage of resin cements may bring about invasive stresses in the tooth and restoration interface. If thin cement layer cannot stand high stresses, there may be a break in bonding. By applying dentin bonding agents a hermetic cover is created between resin and tooth structure, postoperative sensitivity is prevented and adhesion is strengthened (13).

Resin cements chemically bond to etched, silane-treated porcelain. One part of resin cements is bonded to the surface of prepared tooth and one part is bonded to etched and silane-treated porcelain so the stress on tooth is diffused. Based on a good number of laboratory and clinical researches, it can be suggested that resin cements are the best choice for the cementation of full ceramic restorations $(3,9)$. Furthermore resin cements can form a better bonding with metal alloys sanded via micromechanical retention (6).

Certain resin cements contain ytterbium trifluoride and can make some amount of fluoride releasing. Some, on the other hand contain fluorosilicate fillers. Still resin cements lack any fluoride releases with significant level (6). Film thickness may be relatively greater than the other cements. Pulpal biocompatibility however may be particularly problematic in deep penetrations. Resin cements necessitate more sensitive techniques than conventional cements and they have higher costs (3).

In situations where there is no optimal retention and resistance in preparation, resin cements are more useful than conventional cements (6). Particularly in cementation of full ceramic crown restorations or metal-fused restorations prepared for conic cut or short clinic crown long tooth surfaces, resin-based luting cements are preferred more and these cements are advantageous in the other undesired geometric configurations as well (14).

The ability of luting multiple structures together, high resistance, less solubility inside mouth, and color options make resin cements an alternative cement in luting aesthetical restorations $(6,19)$. They can be used in cementation of composite inlays and onlays, full ceramic inlays and onlays, veneers, crowns, bridges and fiber-forced restorations. Resin cements that are polymerized chemically are recommended for the cementation of resin bonded bridges (Maryland type) (6) and ceramic crowns inhibiting light penetration (10). Resin cements that are polymerized via light are used in luting ceramic or composite laminates that allows full penetration of visible light, with thickness less than 1,5-2 $\mathrm{mm}$ and having translucent structure (10).

Dual cured resin cements are used in restorations where restoration is translucent only enough to allow the penetration of little light but with a thickness (more than 1,5-2 mm) that does not allow polymerization with light only (10).

\section{Adhesive Resin Cements}

Today many of the resins that are termed as adhesive are not actually with adhesive attributions. Only adhesive resins with monomers containing 4META and MDP have adhesive quality (9).

In the early 1980s, conventional Bis-GMA resin cement was modified by adding a phosphate ester to the monomer component, introducing to dentistry a unique group of resin luting agents that have a degree of chemical bonding as well as a micromechanical bonding to tooth structure and base metal alloys. The first product marketed, Panavia, contained the bifunctional adhesive monomer MDP (10-methacryloyloxydecyl dihydrogen phosphate) and was a powder-liquid system (3). Bond strength to etched base metal greatly exceeded that to tooth and Panavia quickly became the luting agent of choice for resin retained fixed partial dentures (3).

In 1994, Panavia was modified to include a dentin/enamel primer containing hydroxethyl methacrylate (HEMA), N-methacryloyl 5aminosalicylic acid and MDP, intended to improve bond strength to dentin. Under a new name, Panavia 21, it was marketed as a two-paste system 
that offered three shades: tooth colored (TC, translucent), white (EX, semitranslucent), and opaque (OP). Panavia 21's polymerization required exclusion of oxygen, and a covering gel was provided. The current product, Panavia $F$ is a twopaste system that is dual-cured, self-etching and self-adhesive, plus fluoride-releasing (3).

Before the introduction of Panavia, Bis-GMA composite was modified by decreasing filler and adding $\quad \% 3 \quad$ 2-hydroxy-3b-napthoxypropyl methacrylate in methyl methacrylate with 4methacryloyloxyethyl trimellitate anhydride (4META) and tri-n-butyl borane and marketed as C\&B Metabond (3). C\&B Metabond has physical characteristics similar to other resin cements, but also has an extremely high tensile strength, which is useful for providing retention in restorative situations where less than optimal conditions exist.
It is a powder/liquid auto-curing system and may be used for resin bonded prostheses (23).

Panavia and C\&B Metabond represent several available unique adhesive resin luting agents of various compositions that can help provide adequate retention for crowns and prostheses where less than ideal retention exists (3). The strong cohesion forces in the specific net structure of adhesive resin allow a better stress distribution on the surface of restored tooth (10).

These materials are usually expensive and demand sensitive technique, difficult to clean up when set, and they have no long shelf lives $(6,17)$.

Table 1. Varieties of contemporary permanent luting agents

\begin{tabular}{|c|c|c|}
\hline Cement Type & Product & Company (Location) \\
\hline \multirow{7}{*}{$\begin{array}{l}\text { Resin Modified Glass } \\
\text { Ionomer Luting Cement }\end{array}$} & Vitremer Luting Cement & 3M Dental Products, USA \\
\hline & Fuji Plus & GC Dental Industrial Corp, USA \\
\hline & Fuji II LC & GC Dental Industrial Corp, USA \\
\hline & Fuji Ortho LC & GC Dental Industrial Corp, USA \\
\hline & Photac Fil & 3M ESPE, USA \\
\hline & Photac Bond & 3M ESPE, USA \\
\hline & Pro Tec Cem & Ivoclar, Vivadent, Liechtenstein \\
\hline $\begin{array}{l}\text { Polyacid Modified } \\
\text { Composite Resin Cement }\end{array}$ & Dyract CEM plus & Dentsply, USA \\
\hline \multirow{4}{*}{ Resin Cement } & Variolink II & Ivoclar, Vivadent, Liechtenstein \\
\hline & Ultra-Bond Plus Resin Cement & Den-Mat, Santa Maria \\
\hline & Duo-Link & Bisco, USA \\
\hline & C\&B Cement & Bisco, USA \\
\hline \multirow{7}{*}{ Adhesive Resin Cement } & RelyX Unicem & 3M ESPE, USA \\
\hline & RelyX U100 & 3M ESPE, USA \\
\hline & RelyX ARC & 3M ESPE, USA \\
\hline & Panavia F 2.0 & Kuraray, Japan \\
\hline & Panavia 21 & Kuraray, Japan \\
\hline & C\&B Metabond & Parkell, USA \\
\hline & Clearfil SA Cement & Kuraray, Japan \\
\hline
\end{tabular}




\section{Conclusion}

Restorative dentistry has been going through continuous changes as an outcome of clinical applications and development of new materials. Modern dentistry have a wide variety of application products differing from each other in content and physical attributions $(5,8)$. Therefore it may pose difficulty for dentists to make a choice amongst so many alternative products (15).

Presently there is a rapid development in aesthetical restorative materials and adhesive systems enabling these materials to bond on tooth (18).

Modern dentistry services which can no longer be provided through conventional water based luting cements have become diversified due to the advantages of adhesive techniques (10).

A 2001 survey indicated that many clinicians are now exclusively using newer resin-modified glass-ionomer and resin luting materials based primarily on ease of use, reasonable retention, and low to no postoperative sensitivity (3). However conventional cementation and adhesive cementation are, let alone being conflicting, complementing each other. The choice should be based on the type and design of planned restoration because none of the present products possesses all qualities of an ideal luting agent (10).

Each cement type has different physical, mechanical and biological features arising from its own chemical structure. That is why one single cement type alone is not sufficient for daily clinical applications. To achieve a clinical success, any clinician is expected to be aware of the qualities, advantages and disadvantages of each type of cement and conduct their clinical applications.

\section{References}

1. McCabe JF, Walls AWG. Applied Dental Materials. 9th edition. Oxford: Blackwell Publishing; 2008. p. 257-288.

2. Önal B.Simanlar. Restoratif Diş Hekimliğinde Maddeler ve Uygulamaları.1st edition. İzmir: Ege Üniversitesi Dişhekimliği Fakültesi Yayınları; 2004. p.1-145.

3. Hill EE. Dental cements for definitive luting: a review and practical clinical considerations. Dent Clin N Am 2007; 51:643-658.

4. Rosenstiel SF, Land MF, Crispin BJ. Dental luting agents: A review of the current literature. J Prosthet Dent 1998; 80:280-301.
5. O'Brien WJ. Dental materials and their selection. 3rd edition. Canada: Quintessence Publishing; 2002. p.132-154

6. Diaz-Arnold AM, Vargas MA, Haselton DR. Current status of luting agents for fixed prothodontics. J Prosthet Dent 1999; 81:135-141.

7. Aydın M,Gür H.Sabit Protezlerde Simantasyon. Dişhekimliği Klinik Dergisi 1997; 10(4):239-243.

8. Pegoraro TA, Da Silva NRFA, Carvalho RM. Cements for use in esthetic dentistry. Dent Clin N Am 2007; 51:453-471.

9. Eskimez Ş, İzgi AD. Rezin Simanlar. Adeziv Köprüler ve Klinik Uygulamaları.1st edition. İstanbul: Quintessence Yayıncllı; 2008. p.149160.

10. Zaimoğlu A, Can G. Sabit Protezler. Ankara: Ankara Üniversitesi Diş Hekimliği Fakültesi, 2004.p.239-267.

11. Guggenberger R, May R, Stefan KP. New trends in glass-ionomer chemistry. Biomaterials 1998; 19:479-483.

12. Attar N, Tam LE, McComb D. Mechanical and physical properties of contemporary dental luting agents. J Prosthet Dent 2003; 89:127-134.

13. Öztürk AN, Aykent F.Dentin Bonding Ajanlar ve Simantasyon. Cumhuriyet Üniversitesi Dişhekimliği Fakültesi Dergisi 2001;4(2):128-131.

14. Levent $H$, Oruç $A Z$. Rezin esaslı yapıştırma simanları ile yapıştırılan metal destekli kronlarda mikrosızıntının değerlendirilmesi. GÜ Dişhek Fak Derg 2004;21(1):19-22.

15. Paradella TC. Current adhesive systems in dentistry - what is being said and researched. Odontologia. Clín.-Científ., Recife 2007; 6 (4): 293-298

16. 16. Milutinovic-Nikolic AD, Medic VB, Vukovic ZM. Porosity of different dental luting agents. Dental Materials 2007;23:674-678.

17. Baydaş S. Kron-Köprü Protezleri. Erzurum: Özyurt Matbaacilık; 2005.p.127-133.

18. Akören AC, Üçtaşlı S. Farklı Porselen İnley Sistemleri ve Farklı Yapıştırma Simanlarının Mikrosızıntı Üzerine Etkileri. T Klin J Dental Sci 1998;4:100-105.

19. Miguel A, Macorra JC, Nevado S, Gomez J. Porosity of resin cements and resin-modified glass-ionomers. Am J Dent 2001; 14:17-21.

20. Smith DC. Development of glass-ionomer cement systems. Biomaterials 1998;19:467-478.

21. Shinkai K, Suzuki S,Katoh Y. Effect of filler size on wear resistance of resin cement. Odontology 2001;89:41-44.

22. Christensen GJ. Should resin cements be used for every cementation? Journal of ADA 2007; 138:817-819.

23. Ertuğrul $\mathrm{HZ}$, Ismail $\mathrm{YH}$. An in-vitro comparison of cast metal dowel retention using various luting agents and tensile loading. J Prosthet Dent 2005; 93(5):446-452. 